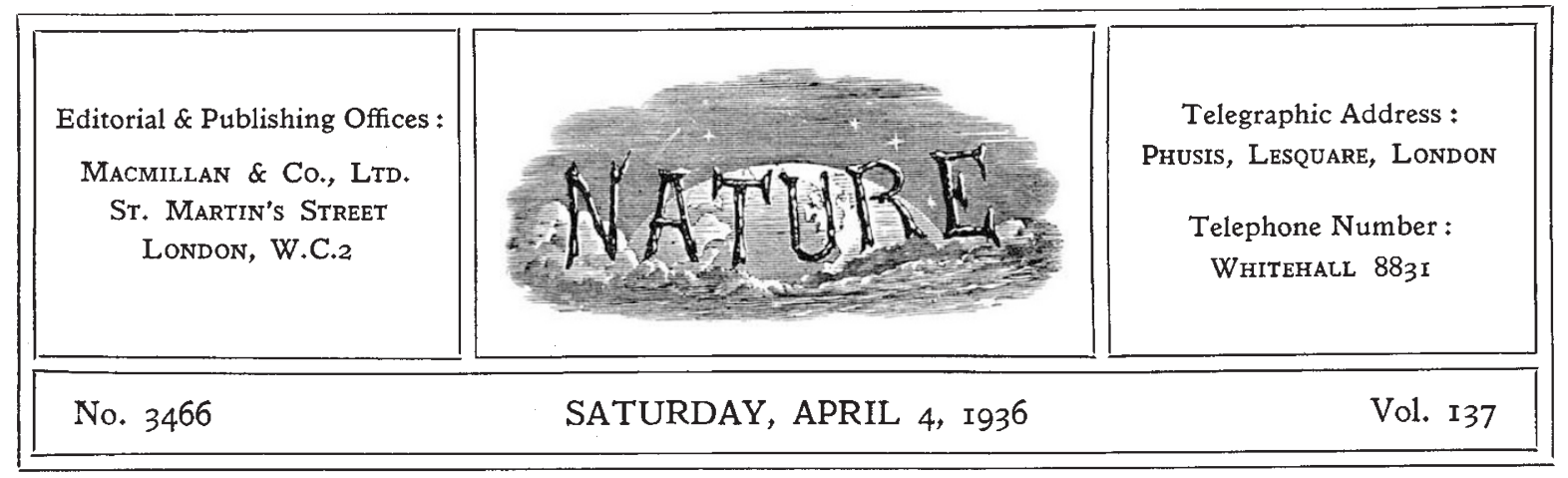

\title{
Petroleum in Britain
}

CONSENSUS of geological opinion has long 4 been opposed to the prospect of finding commercial oil-pools in England. Ever since the failure of war-time effort to locate petroleum resources (Hardstoft excepted as a modest memorial preserved from decay, by almost uncanny, albeit slender persistence), there has been nothing stirring in relevant geological knowledge of England to change such opinion. The last two decades have been productive of outstanding geological and oil-engineering achievements elsewhere, of progressive increase of knowledge of conditions governing the natural history and favourable loci of subterranean oil-pools; but they cannot by any stretch of proved fact or reasoned hypothesis be claimed as having sponsored hitherto unsuspected data to upset deeprooted conviction in enlightened technical circles of Britain's unfortunate inability to reveal indigenous oil in industrial quantity.

Recurrent enterprise, of a highly speculative character as 'wild-catting' mostly is, from time to time has focused public attention on activities in Kent, Sussex and elsewhere. Fanned by the breeze of a good, though often ill-informed press, the flame of prophecy of discovery of petroleum in quantities sufficient to make Britain independent of foreign supplies spread rapidly, especially in 1933. Confirmation of predictions from extraBritish sources was not lacking, any more than it was when the war-time oil-drive commenced; whatever success their efforts unquestionably merited in foreign lands, the impression was widespread that there was a certain ineptitude on the part of British oil geologists to understand their own territory, and to this extent carefully weighed opinions and published statements were ignored. The position developed, as inevitable, into one of first-class public importance. Geological discussion yielded gladly to political controversy on the situation, which culminated in the passing of the Petroleum Act in 1934.

Insofar as the Act goes, it is unquestionably a sound measure, providing as it does for organised and licensed development by the State, and a direct national interest in whatever may ultimately be found as petroleum. Its implications, however, were from the layman's point of view possibly not so sound, since the publicity given to the matter in Parliament and outside naturally suggested by inference, if not as inspired official opinion, that there did indeed exist possibilities of commercial oil deposits in England. This was certainly not the intention of the Act.

None the less, it did place a moral obligation on oil technologists in general and British oil companies in particular, to re-examine the whole question of possibilities and to consider a reasonable scheme whereby, so far as humanly possible, the doubt could be settled. What more natural than that one of our leading British oil companies should take the initiative and, in the same spirit of cautious enterprise characteristic of its operations elsewhere, formulate and put into practice a scheme of widespread testing of potentially favourable areas in southern and south-western England?

On March 30, the Anglo Iranian Oil Company, through its subsidiary, the D'Arcy Exploration Company, commenced drilling operations on the first test-well to be sunk under the provisions of the 
1934 Act, at Paulsgrove, on the slopes of Portsdown Hill overlooking Portsmouth. The rig is of a modern rotary type, 135 feet high, with a loading capacity of 400 tons, and stated to be capable of drilling to a depth of nearly three miles.

In his opening speech at the ceremony of setting in motion these works, Sir John Cadman referred to the enterprise, which all hoped would be eventually of great national importance, as "first and foremost a business venture, based on scientific observation, and organized with all the elaboration of detail that engineering skill and experience can suggest". He referred to the exploration company "as adventurers into the unknown, where, in the language of the oilfield, 'only the drill can tell" ".

From the strictly geological point of view, we may anticipate the drill telling of the bold structure of the Portsdown anticline which forms the conspicuous chalk background to the historic city. It may tell, also, of a sequence of rocks of which British geologists familiar with southern England stratigraphy could make a fairly shrewd guess both as to character and disposition. It may do much to strengthen conceptions of the subWealden structure. It will focus attention on Upper Jurassic possibilities, in particular the sorely tried and much over-rated Kimmeridge Clay. It will perhaps offer some explanation of the not far-distant natural gas and petrol smell of associated strata at Heathfield. It may even, in three miles of deep drilling, pierce totally unexpected and much older rock structures, including Carboniferous.

All this is reasonable. But let us not build too optimistically on the results in terms of oil. Rather let us hope for the unexpected and applaud the efforts now being made and the patriotism behind them. Should failure be the reward, which every British geologist, whatever may be his convictions, would doubly deplore in the interests both of science and the State, then may it be that science, in particular geology, may benefit lastingly by the knowledge thus made available, and possibly, as in the case of the sub-Wealden boring, industry benefit by discovery of a new mineral deposit, other than petroleum, of economic worth.

\section{Pre-nuptial Medical Examination}

$\mathrm{T}$ HOUGH vitamins and minerals are fashion. able ingredients of well-informed and polite conversation, by most people reproduction is not mentioned : it is disturbing, even repulsive. Yet men and women do mate and reproduce, and the State which is beginning to regard the child as a liability will sooner or later be forced to exhibit a very lively interest both in the number and the quality of the children that are born to be fed, housed, educated and employed or not employed.

Pre-nuptial certificates are even now demanded in certain countries, though usually by them eugenic considerations are completely disregarded. In Turkey, for example, marriage is forbidden to persons affected with active venereal diseases, mental disease or leprosy; whilst the marriage of persons afflicted with advanced and transmissible tuberculosis is delayed for as long as a year. In Norway there is a somewhat similar law prohibiting the marriage of a syphilitic, but in the case of other venereal diseases, epilepsy and leprosy, the other party to the marriage must be informed, and both parties warned by a physician of the possible consequences of marriage. On the schedule used in connexion with these cases there are questions relating to consanguinity, and information concerning the prohibition of marriages of close relatives. In Germany certificates of health before marriage are demanded of those persons applying for marriage loans; and for these, fairly comprehensive details of the family and personal medical history are required.

In Great Britain, it may be remembered, Lord Kilmaine, in the House of Lords on November 14 of last year, moved a resolution favouring the compulsory exchange of health certificates before marriage. It was suggested that there should be four kinds of such certificates: $(a)$ when both parties are perfectly fit to marry and to raise a family, (b) when the marriage should be delayed for 3-6 months, $(c)$ which permitted marriage without parentage, and $(d)$ which prohibited marriage altogether. Lord Kilmaine appeared to think that an actual medical examination in these cases was unnecessary, and that it would be enough if the two people concerned merely answered the questions of the physician concerning their general health and family history. As was to be expected, 
1934 Act, at Paulsgrove, on the slopes of Portsdown Hill overlooking Portsmouth. The rig is of a modern rotary type, 135 feet high, with a loading capacity of 400 tons, and stated to be capable of drilling to a depth of nearly three miles.

In his opening speech at the ceremony of setting in motion these works, Sir John Cadman referred to the enterprise, which all hoped would be eventually of great national importance, as "first and foremost a business venture, based on scientific observation, and organized with all the elaboration of detail that engineering skill and experience can suggest". He referred to the exploration company "as adventurers into the unknown, where, in the language of the oilfield, 'only the drill can tell" ".

From the strictly geological point of view, we may anticipate the drill telling of the bold structure of the Portsdown anticline which forms the conspicuous chalk background to the historic city. It may tell, also, of a sequence of rocks of which British geologists familiar with southern England stratigraphy could make a fairly shrewd guess both as to character and disposition. It may do much to strengthen conceptions of the subWealden structure. It will focus attention on Upper Jurassic possibilities, in particular the sorely tried and much over-rated Kimmeridge Clay. It will perhaps offer some explanation of the not far-distant natural gas and petrol smell of associated strata at Heathfield. It may even, in three miles of deep drilling, pierce totally unexpected and much older rock structures, including Carboniferous.

All this is reasonable. But let us not build too optimistically on the results in terms of oil. Rather let us hope for the unexpected and applaud the efforts now being made and the patriotism behind them. Should failure be the reward, which every British geologist, whatever may be his convictions, would doubly deplore in the interests both of science and the State, then may it be that science, in particular geology, may benefit lastingly by the knowledge thus made available, and possibly, as in the case of the sub-Wealden boring, industry benefit by discovery of a new mineral deposit, other than petroleum, of economic worth.

\section{Pre-nuptial Medical Examination}

$\mathrm{T}$ HOUGH vitamins and minerals are fashion. able ingredients of well-informed and polite conversation, by most people reproduction is not mentioned : it is disturbing, even repulsive. Yet men and women do mate and reproduce, and the State which is beginning to regard the child as a liability will sooner or later be forced to exhibit a very lively interest both in the number and the quality of the children that are born to be fed, housed, educated and employed or not employed.

Pre-nuptial certificates are even now demanded in certain countries, though usually by them eugenic considerations are completely disregarded. In Turkey, for example, marriage is forbidden to persons affected with active venereal diseases, mental disease or leprosy; whilst the marriage of persons afflicted with advanced and transmissible tuberculosis is delayed for as long as a year. In Norway there is a somewhat similar law prohibiting the marriage of a syphilitic, but in the case of other venereal diseases, epilepsy and leprosy, the other party to the marriage must be informed, and both parties warned by a physician of the possible consequences of marriage. On the schedule used in connexion with these cases there are questions relating to consanguinity, and information concerning the prohibition of marriages of close relatives. In Germany certificates of health before marriage are demanded of those persons applying for marriage loans; and for these, fairly comprehensive details of the family and personal medical history are required.

In Great Britain, it may be remembered, Lord Kilmaine, in the House of Lords on November 14 of last year, moved a resolution favouring the compulsory exchange of health certificates before marriage. It was suggested that there should be four kinds of such certificates: $(a)$ when both parties are perfectly fit to marry and to raise a family, (b) when the marriage should be delayed for 3-6 months, $(c)$ which permitted marriage without parentage, and $(d)$ which prohibited marriage altogether. Lord Kilmaine appeared to think that an actual medical examination in these cases was unnecessary, and that it would be enough if the two people concerned merely answered the questions of the physician concerning their general health and family history. As was to be expected, 